\title{
Blue LED Irradiation of lodonium Ylides Gives Diradical Intermediates for Efficient Metal-free Cyclopropanation with
}

\section{Alkenes}

\author{
Tristan Chidley, ${ }^{[a]}$ Islam Jameel, ${ }^{[a]}$ Shafa Rizwan, ${ }^{[a]}$ Philippe A. Peixoto, ${ }^{[b]}$ Laurent Pouységu,${ }^{[b]}$ \\ Stéphane Quideau, ${ }^{*[b]}$ W. Scott Hopkins ${ }^{*[a]}$ and Graham K. Murphy ${ }^{*[a]}$
}

\begin{abstract}
A facile and highly chemoselective synthesis of doubly activated cyclopropanes is reported where mixtures of alkenes and $\beta$-dicarbonyl-derived iodonium ylides are irradiated with light from blue LEDs. This metal-free synthesis gives cyclopropanes in yields up to $96 \%$, is operative with cyclic and acyclic ylides, and proceeds with a variety of electronically-diverse alkenes. Computational analysis explains the high selectivity observed, which derives from exclusive HOMO to LUMO excitation, instead of free carbene generation. The procedure is operationally simple, uses no photocatalyst, and provides access in one step to important building blocks for complex molecule synthesis.
\end{abstract}

Recently, the use of hypervalent iodine(III) (HVI) reagents in organic chemistry has undergone tremendous growth, owing to the inherent advantages of mild reaction conditions and broad reactivity, and of recyclable, environmentally-benign byproducts. ${ }^{[1]}$ Cutting edge strategies towards reactions that are catalytic in iodoarene have been developed, including catalytic asymmetric variants. ${ }^{[2]}$ In addition, recent efforts to merge visible light-mediated photochemistry with HVI-based reactions has revealed new and exciting potential for organic synthesis. ${ }^{[3]}$ However, compared with the major achievements realized for photoredox catalysis with transition metal complexes, ${ }^{[4]}$ the intersection of HVI-mediated reactions and visible light photoredox catalysis or photoactivation is still in its infancy.

Our interest in HVI-mediated reactions stems from the movement towards safer and more sustainable organic synthesis practices. By developing new processes in which iodonium ylides serve as diazonium ylide surrogates, ${ }^{[5]}$ we exploit the increased and often complementary reactivity that they display, which originates from their hypervalent bonding. lodonium ylides are synthetically versatile, ${ }^{[6]}$ readily undergoing ionic reactions ${ }^{[7]}$ and serving as precursors in $\mathrm{C}-\mathrm{H}$ insertion, ${ }^{[8]}$ cycloaddition, $^{[9]}$ cyclopropanation $^{[10]}$ or tandem reactions thereof, ${ }^{[11]}$ as both racemic and asymmetric processes. ${ }^{[10 f, 12]}$ The reliance on the use of $\beta$-dicarbonyl or similarly $\beta$-distabilized species to generate iodonium ylides render these unique carbene precursors ideally functionalized for the synthesis of important synthetic motifs, such as doubly activated cyclopropanes. $^{[13,14]}$

[a] T. Chidley, I. Jameel, S. Rizwan, Prof. Dr. W.S. Hopkins and Prof. Dr. G.K. Murphy

Department of Chemistry, University of Waterloo, Waterloo, Ontario, Canada, N2L3G1

E-mail: graham.murphy@uwaterloo.ca

[b] Dr. Philippe A. Peixoto, Prof. Dr. L. Pouységu, Prof. Dr. S. Quideau Univ. Bordeaux, ISM (CNRS-UMR 5255), 351 cours de la Libération, Talence F-33405 Cedex, France lodonium ylides can be converted to singlet carbenes under irradiation using a mercury $(\mathrm{Hg})$ lamp, and the groups of Hadjiarapoglou, ${ }^{[9 c]}$ Matveeva, ${ }^{[7,15]}$ and Spyroudis ${ }^{[9 f, 16]}$ have reported examples of cyclopropanation and related cycloaddition events. These reactions thus proceed via free carbenes, which are formed upon cleavage of the ylide C-IPh bond, but the heat generated by the lamp is often an unavoidable source of technical complications and chemical selectivity issues. For example, Hadjiarapoglou showed that irradiating a iodonium ylide 1a with a $\mathrm{Hg}$ lamp leads exclusively to a dihydrofuran in $96 \%$ yield, in part due to the heat generated during the reaction, which is sufficient to isomerize any of cyclopropane $\mathbf{3 a}$ formed (Scheme 1a). In this regard, light-emitting diodes (LEDs) constitute new tools for testing the reactivity of iodonium ylides, as light irradiation in the lower-energy $400-500 \mathrm{~nm}$ (violet-blue) range can be easily achieved without significant heating, hence enabling the practical, convenient and selective generation of reactive intermediates under much milder conditions. Recently, Davies and Jurberg reported the photochemical decomposition of aryldiazoacetates with blue LEDs in the presence of styrene. ${ }^{[17,18]}$ however, these cyclopropanation reactions were only successful with donor/acceptor diazo derivatives, as both monostabilized ethyl diazoacetate and distabilized dimethyl 2diazomalonate derivatives did not absorb in the blue light region. Though they often exhibit similar chemical reactivity, iodonium ylides are zwitterionic and structurally distinct from diazo compounds, because their ylene resonance forms contribute little to their $\mathrm{C}-\mathrm{I}$ bonding. ${ }^{[19]}$ Thus, we envisioned that irradiating distabilized iodonium ylides with lower-energy visible light could provide an entry into metal-free carbenoid-type reactivity. Herein, UV-Visible spectroscopy, computational analysis and experimentation were used to elucidate how distabilized cyclic and acyclic iodonium ylides could react with alkenes under blue LED irradiation to provide cyclopropanes (Scheme 1b).

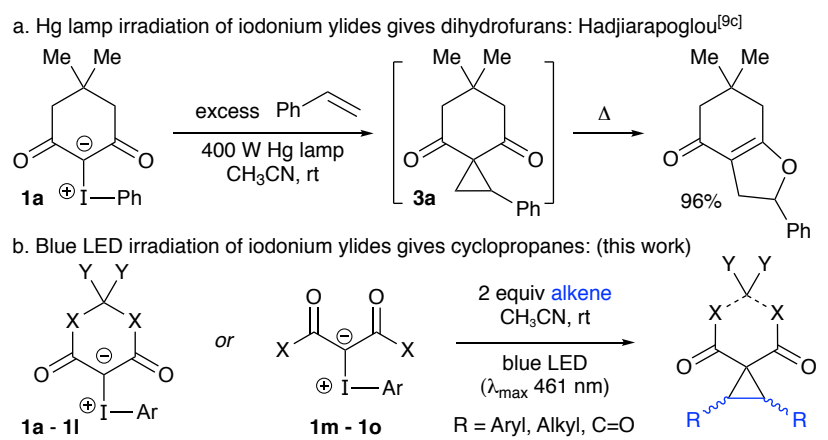

Scheme 1. Light-mediated reactions of iodonium ylides. 
We began this study by recording the UV-Vis absorption spectra of the dimedone-derived iodonium ylide $1 \mathrm{a}$ at $0.1 \mathrm{M}$ and $0.03 \mathrm{mM}$ concentrations (Figure $1 \mathrm{a}$ and $1 \mathrm{~b}$, also see Figure SI1). When overlaid with the emission spectrum of the RGB LEDs, it is clear that excitation of 1a can only occur in the blue region (see inset). We then tested a series of related iodonium ylides possessing substituents on the phenyl ring of the iodoarene motif, but we found little-to-no variation in their UV-Vis absorption spectra at $0.1 \mathrm{M}$ with iodoarenes equipped with $p$ tolyl (1b), $p$-Cl (1c), $p$-CN (1d), 2,6-dimethoxy-4-methyl (1g) and even with the 2-naphthyl (1h) as compared to that of the parent iodonium ylide 1a (see Figure SI-10). Changing the $\beta$-dicarbonyl region of the ylide resulted in more significant changes in their absorption spectra. Progressing from the dimedone-(1a), to the ketoester-(1i), to the diester-(1j) derived ylides showed an increasing blue shift (see Figure SI-11), and we anticipated that the decreasing overlap with the blue LED emission spectrum would result in increasingly longer reaction rates for these ylides.

To explore the electronic spectroscopy from a fundamental standpoint, we conducted a computational study of selected iodonium ylides at the time-dependent (TD) DFT level of theory. ${ }^{[20]}$ First, a search for optimal molecular geometry was performed at the B3LYP/6-311+G(d,p) level of theory. ${ }^{[21]}$ Upon identifying the global minimum geometry for each ylide, the optimal ground state structure was employed for TD-DFT calculations of the ten lowest-energy excited electronic states. An example of the output from these calculations is provided in Figure 1c, which plots the predicted UV-Vis spectrum for $\mathbf{1 a}$ as relative absorption cross-section versus wavelength. In this, and all other cases examined, we found that the blue LED irradiation drives HOMO to LUMO excitation. For $1 \mathrm{a}$, the HOMO to LUMO band system is predicted to be the most intense of those calculated $(332 \mathrm{~nm})$, and it is well separated from those of higher energies (i.e., shorter wavelengths). While the relative intensity and absorption maximum of the HOMO to LUMO excitation did vary somewhat across the series of iodonium ylides (see Figures SI-1 to SI-6), the nature of the electronic excitation was essentially the same for each iodonium ylide. Specifically, for $\mathbf{1 a}$, the HOMO of the ylide is predominantly associated with electron density at the carbonyl oxygens and the ylide carbon (Figure 1d). Excitation to the LUMO promotes one electron from the HOMO to an orbital that is predominantly associated with the iodine centre. This interpretation is supported by natural population analysis, ${ }^{[22]}$ which indicates that $0.26 e$ of electron density is transferred to iodine upon irradiation of the ylide (average determined from ylides $\mathbf{1} \mathbf{a}, \mathbf{b}, \mathbf{g}-\mathbf{j}$; see Table $\mathrm{SI}-1$ ). Therefore, unlike related diazo compounds, $\beta$-dicarbonylderived iodonium ylides are expected to absorb blue light and to generate 1,2-diradical species, such as $\mathbf{A}$ (with unpaired electron density predominantly on the iodine atom and the ylidic carbon), instead of undergoing heterolytic cleavage to produce free carbenes.

To test the chemical reactivity of iodonium ylides under blue LED $\left(\lambda_{\max } 461 \mathrm{~nm}\right)$ irradiation, we constructed a multi-slot reactor (see Figure $\mathrm{SI}-15$ ) in which the reaction vial is placed directly above the LED, thus minimizing and standardizing the distance between the two. We found that irradiating ylide 1a in the presence of 1 equiv of styrene for $2.5 \mathrm{~h}$ in $\mathrm{CDCl}_{3}$ gives cyclopropane $3 \mathbf{a}$ in $71 \%$ NMR yield, without formation of the free carbene-derived dimer product $\mathbf{2 a}$ (Table 1, entry 1 ; see also Table SI-2). Using 2 equiv of styrene led to $3 \mathbf{a}$ in $96 \%$ yield, and
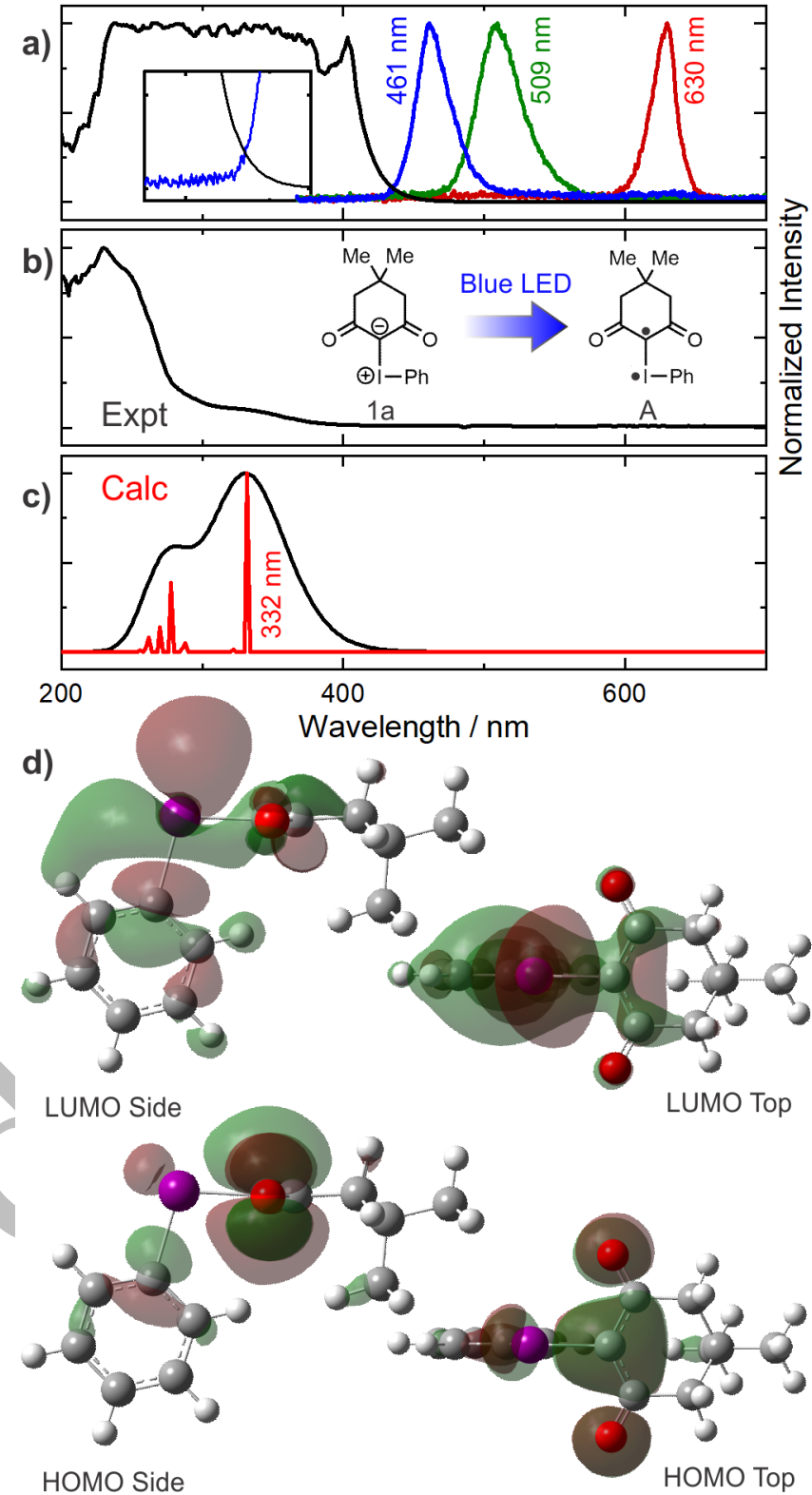

Figure 1. a) UV-Vis spectrum of $1 \mathrm{a}$ at $0.1 \mathrm{M}$, overlaid with emission spectra of RGB LEDs and their $\lambda_{\max }$ values. b) UV-Vis spectrum of $1 \mathrm{a}$ at $0.03 \mathrm{mM}$. c) Calculated UV-Vis spectrum of $1 \mathrm{a}$; the dominant $332 \mathrm{~nm}$ absorption corresponds to a HOMO to LUMO transition. d) Calculated HOMO of $\mathbf{1 a}$ (bottom), showing electron density predominantly on the $\beta$-dicarbonyl motif, and calculated LUMO of $1 \mathrm{a}$ (top), showing predominantly orbital density on the iodine atom. Upon blue LED irradiation, the LUMO becomes populated with a single electron, generating the diradical species $\mathbf{A}$ depicted in $\mathbf{b}$ ).

very little improvement was realized when using 4 equiv of styrene (entries 2,3). We found $\mathrm{CHCl}_{3}, \mathrm{CH}_{2} \mathrm{Cl}_{2}$ or $\mathrm{CH}_{3} \mathrm{CN}$ to be also effective solvents, giving $3 a$ in similar yields within $2 \mathrm{~h}$; however, when the polar protic solvent $\mathrm{MeOH}$ was used, neither 2a, 3a or $\mathrm{O}-\mathrm{H}$ insertion products was observed (entries 4-7). Since 1a was much more soluble in $\mathrm{CH}_{3} \mathrm{CN}$ than in the other solvents, it was chosen as the optimal reaction solvent. Using $\mathrm{CH}_{3} \mathrm{CN}$, 3a was produced and isolated in $95 \%$ yield (Table 1 , entry 6). As expected (see Figure 1a), irradiating the reaction mixture with either red or green LEDs for $24 \mathrm{~h}$ resulted in no ylide consumption, although subsequent irradiation with blue LEDs afforded $3 \mathbf{a}$ in $63 \%$ and $79 \%$ yields, respectively (entries $8,9)$. Irradiating 1a with blue LEDs for $72 \mathrm{~h}$ in the absence of 
styrene led to complete ylide decomposition (entry 10), again without formation of the free carbene-derived dimer product $2 a^{[8 c]}$ Attempting the reaction under ambient light for $24 \mathrm{~h}$, or in the dark for $72 \mathrm{~h}$, resulted in quantitative recovery of $1 \mathrm{a}$ (entries 11,12). Therefore, irradiating $\mathbf{1 a}$ with blue light leads to a mild and highly efficient metal-free cyclopropanation that, unlike related processes employing UV lamps, is entirely chemoselective for the formation of cyclopropane $\mathbf{3 a}$ without any evidence of free carbene intermediates or of isomerisation to the dihydrofuran product (see Scheme 1a).

We then evaluated the impact of the iodoarene substitution pattern on the rate and efficacy of the cyclopropanation reaction by subjecting the dimedone-derived iodonium ylides $1 \mathrm{a}-1 \mathrm{~h}$ to the optimized reaction conditions (Scheme 2 ). In each case, the ylide was consumed within $2.5 \mathrm{~h}$, affording $3 \mathrm{a}$ in yields ranging from 59 to $95 \%$. It is worth noting that no correlation was observed between reaction rates or yields and either the electron-rich or electron-poor character of the substrates. For example, 3a was observed in $87 \%$ and $89 \%$ yields when using either the iodonium ylide $1 \mathrm{f}(p-\mathrm{OMe})$ or $1 \mathrm{e}\left(p-\mathrm{CF}_{3}\right)$. These results are consistent with

Table 1. Optimization of the cyclopropanation reaction.

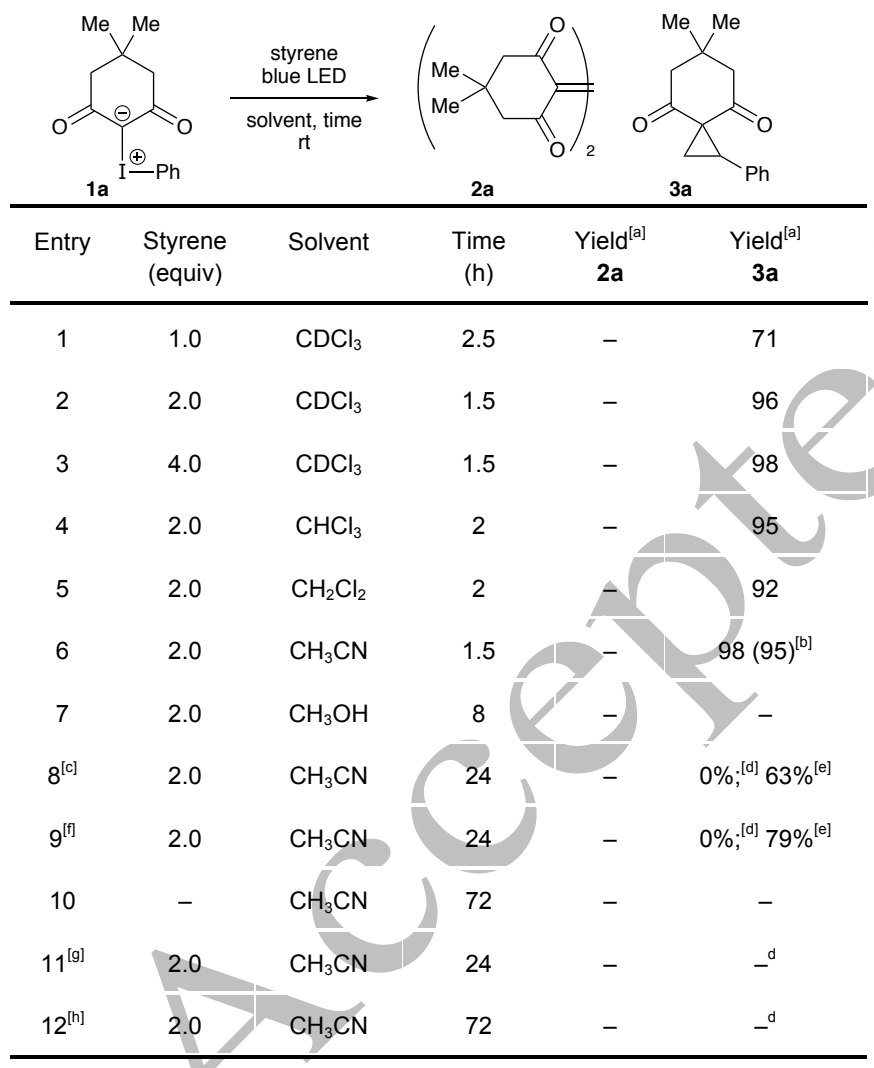

[a] ${ }^{1} \mathrm{H}$ NMR yields using HMDSO as internal standard. [b] Isolated yield. [c] Irradiation with red LED. [d] Quantitative observation of 1a by ${ }^{1} \mathrm{H}$ NMR yield. [e] ${ }^{1} \mathrm{H}$ NMR yield after subsequent blue LED irradiation. [f] Irradiation with green LED. [g] Reaction performed in ambient light. [h] Reaction performed in the dark.

the minimal deviations observed in the UV-Vis absorption spectra of these compounds compared with that of 1a (see Figure SI-10).

We next submitted the ketoester (1i) and diester (1j) analogues of $1 \mathrm{a}$ to the same optimized reaction conditions. A significant decrease in reaction rate was observed, with $1 \mathrm{i}$ being consumed in $4 \mathrm{~h}$ and $1 \mathrm{j}$ only after $24 \mathrm{~h}$, though the yields remained excellent. We were pleased to observe that these ylides did not suffer from decomposition upon prolonged irradiation. Interestingly, both the experimental and predicted UV-Vis spectra of $\mathbf{1 a}, \mathbf{1} \mathbf{i}$ and $\mathbf{1 j}$ showed a blue shift upon increasing ester function incorporation (See Figure SI-11). To probe this effect, we conducted another experiment in which ylide $1 \mathbf{j}$ was subjected to the optimal reaction conditions, but irradiating instead with violet LEDs ( $\lambda_{\max } 397 \mathrm{~nm}$, see Figure SI12). In this case, ylide $1 \mathrm{j}$ was consumed within $1 \mathrm{~h}$, and the expected cyclopropane product 3d was observed in $67 \%{ }^{1} \mathrm{H}$ NMR yield, along with $33 \%$ of the Meldrum's acid dimer $\mathbf{2 b}$ (see Scheme 2). Thus, the chemoselectivity observed using blue light irradiation derives from exclusive photoexcitation into a diradical intermediate, whose generation is not possible when irradiating with either violet LEDs or Hg lamps.
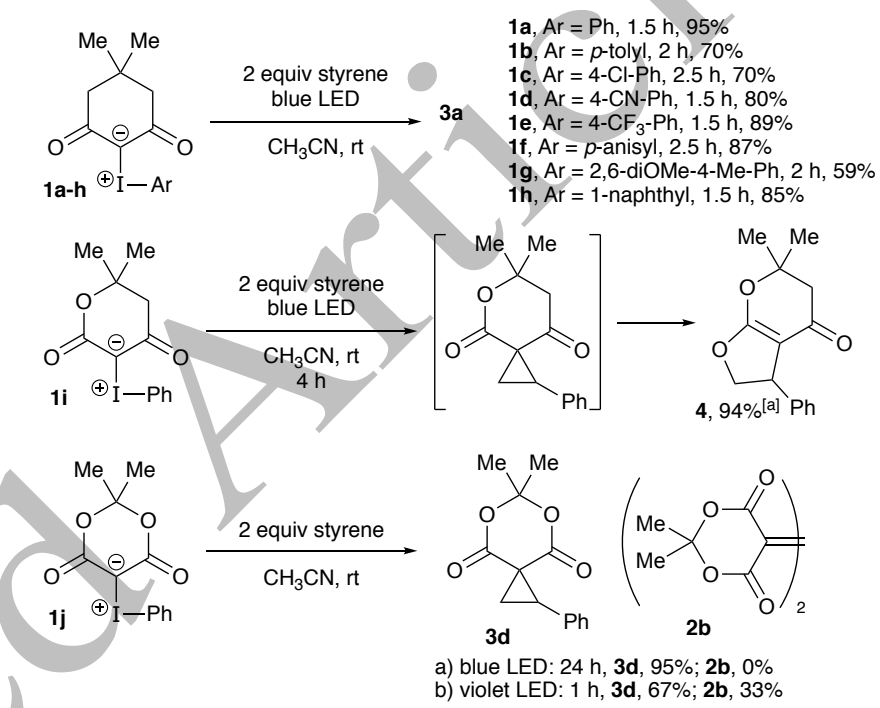

Scheme 2. Testing the various iodonium ylide derivatives. ${ }^{1} \mathrm{H}$ NMR yields using HMDSO as the internal standard. [a] Isomerization to $\mathbf{4}$ occurred during ${ }^{1} \mathrm{H}$ NMR analysis.

The scope of this cyclopropanation reaction was then evaluated with the aim of demonstrating the viability of our iodonium ylides with various alkenes (Scheme 3). ${ }^{[23]}$ Ylide 1a could be efficiently coupled with other styrene derivatives in 1.5 $\mathrm{h}$, and only a modest decrease in yield was observed with the electron-deficient $m-\mathrm{NO}_{2}$ styrene derivative (see $3 \mathbf{b}$ ). The Meldrum's acid-derived ylide $\mathbf{1} \mathbf{j}$ was coupled with other additional styrene derivatives bearing either electron-donating or electron-withdrawing groups. The expected cyclopropane products $3 d$-i were obtained in yields ranging from 72 to $96 \%$, with the fastest reaction rates occurring with the most electronrich alkene. Two other styrenes featuring a biphenyl motif were also viable, leading to $\mathbf{3} \mathbf{j}$ and $\mathbf{3 k}$ in $68 \%$ and $75 \%$ yields after 24 $\mathrm{h}$ of irradiation. Additional substitution on the alkene was also tolerated, with both trans- and cis- $\beta$-methylstyrene reacting to give exclusively the trans-substituted cyclopropane $3 \mathbf{3 1}$ in $85 \%$ and $81 \%$ yield, respectively. ${ }^{[24,25]}$ Ylide $1 \mathbf{j}$ was then reacted with a variety of non-styrenyl alkenes to varying degrees of success. Cyclopentene and cyclohexene led to cyclopropanes $\mathbf{3 m}$ and $\mathbf{3 n}$ in $28 \%$ and $35 \%$ yields, while allylbenzene and 1 -dodecene respectively gave 30 in $34 \%$ yield and $3 p$ in $56 \%$ yield. In each case, full conversion of $1 \mathbf{j}$ was observed, but we were unable to account for the missing mass balance. Ylide 11, which is derived 
from barbituric acid, was also effectively coupled with styrene

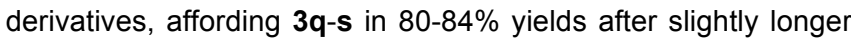
reaction times than those observed for ylide $\mathbf{1 j}$. Acyclic iodonium ylides were then investigated, and the methyl acetoacetatederived ylide $1 \mathrm{~m}$ was coupled with styrene in $19 \mathrm{~h}$ to give $3 \mathrm{t}$ in $82 \%$ yield. The dimethyl malonate-derived ylide $1 \mathrm{n}$ was coupled with styrene in $17 \mathrm{~h}$ or with $\mathrm{N}$-phenylmaleimide in $7 \mathrm{~h}$ to furnish $3 u$ and $3 v$ in 64 and $46 \%$ yields. We observed this ylide $1 \mathrm{~m}$ to undergo significant decomposition upon standing at room temperature, which could be overcome by using 20 equiv of styrene, hence affording $3 \mathrm{u}$ in $81 \%$ yield over $3 \mathrm{~h}$. In the aim of consuming the ylide at a faster rate, we repeated the experiment using violet LED ( $\lambda_{\max } 397 \mathrm{~nm}$ ) irradiation, but $\mathbf{3 u}$ was observed in only $25 \%$ yield after $1 \mathrm{~h}$, along with $27 \%$ of the corresponding free carbene dimer. We also attempted this reaction using the 0 iodoanisole-derived iodonium ylide of methyl acetoacetate $(10),{ }^{[26]}$ which is fully soluble in the reaction mixture, but no improvement was achieved compared with running the reaction as a slurry $(64 \%$ yield, $22 \mathrm{~h})$. The ensemble of the results of this experimental work, even if not exhaustive, clearly shows that this cyclopropanation reaction

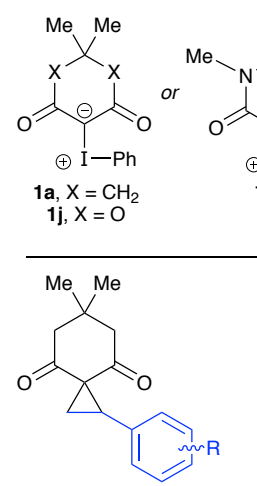

3a, $\mathrm{R}=\mathrm{H}, 1.5 \mathrm{~h}, 95 \%$ 3b, $\mathrm{R}=3-\mathrm{NO}_{2}, 1.5 \mathrm{~h}, 80 \%$
3c, $\mathrm{R}=4-\mathrm{Cl}, 1.5 \mathrm{~h}, 91 \%$

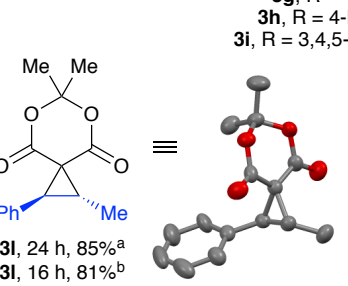

o

$\mathrm{R}_{1}$

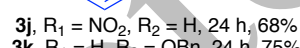
3), $R_{1}=\mathrm{NO}_{2}, \mathrm{R}_{2}=\mathrm{H}, 24 \mathrm{~h}, 68 \%$
$\mathbf{3 k}, \mathrm{R}_{1}=\mathrm{H}, \mathrm{R}_{2}=\mathrm{OBn}, 24 \mathrm{~h}, 75 \%$

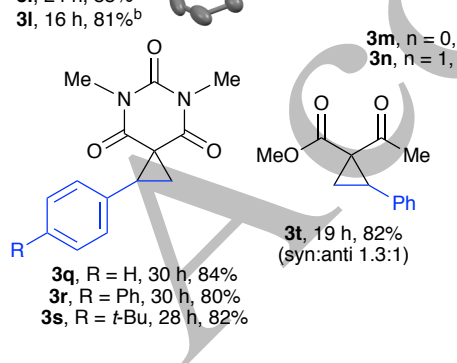

$3 m, n=0,24 h, 28 \%$ $3 m, n=0,24 h, 28 \%$
$3 n, n=1,24 h, 35 \%$

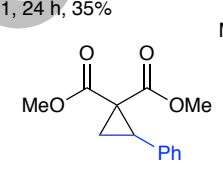

3u, $17 \mathrm{~h}, 64 \%$ 3u, $3 \mathrm{~h}, 81 \%^{\mathrm{c}}$ 3 u, 1 h, $25 \%^{\text {d }}$ 3u, 22 h, $64 \%$ e

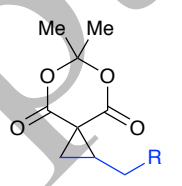

3o, $\mathrm{R}=\mathrm{Ph}, 24 \mathrm{~h}, 34 \%$ 3p, $\mathrm{R}=n-\mathrm{C}_{9} \mathrm{H}_{19}, 36 \mathrm{~h}, 56 \%$

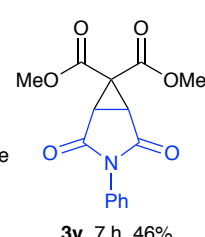

3v, 7 h, $46 \%$

Scheme 3. LED-mediated cyclopropane synthesis. [a] Using trans- $\beta$ methylstyrene. [b] Using cis- $\beta$-methylstyrene. [c] 20 equiv of styrene. [d] Violet LED used. Also $27 \%$ of malonate dimer by ${ }^{1} \mathrm{H}$ NMR. [e] Using soluble ylide 10 .

between $\beta$-dicarbonyl iodonium ylides and alkenes under blue LED irradiation constitutes an efficient and general transformation, which can be performed with either cyclic or acyclic ylides, and with either styrenyl or non-styrenyl alkenes as reaction partners. Reaction rates were generally faster with increasingly electron-rich alkenes, and reaction yields lower using non-styrenyl alkenes.

Further improvements of these cyclopropanation reactions of iodonium ylides were possible through their in situ synthesis from activated methylene compounds and $\mathrm{Phl}(\mathrm{OAc})_{2} .^{[9 \mathrm{~h}, 10 \mathrm{e}, 11 \mathrm{~b}, 27]}$ The rationale behind this possibility is that unstable ylides, which usually decompose upon standing at room temperature, can thus be generated and directly reacted with their alkene partners. To test the feasibility of this experimental option in the context of our photo-initiated process, dimedone $\left(5, X=\mathrm{CH}_{2}\right)$ or Meldrum's acid $(6, X=0)$ were combined base-free with 1 equiv of $\mathrm{Phl}(\mathrm{OAc})_{2}$ and two equivalents of styrene, then submitted to blue LED irradiation (Scheme 4). Under these conditions, 3a was generated in $86 \%$ yield over $1.5 \mathrm{~h}$, and $3 \mathrm{~d}$ in $62 \%$ yield over 20 h. Finally, the methyl $p$-nitrophenylacetate derivative 7 was also tested to check if ylides that would be unstable to isolation and purification would also work. The reaction failed in the absence of base, presumably due to the decreased acidity of the methylene protons relative to that of methylene protons of a $\beta$ dicarbonyl scaffold. Nevertheless, when 4 equiv of $\mathrm{NaH}$ was added, the expected cyclopropane $3 w$ was obtained in $42 \%$ yield, as a 1.7:1 mixture of diastereomers. ${ }^{[28]}$

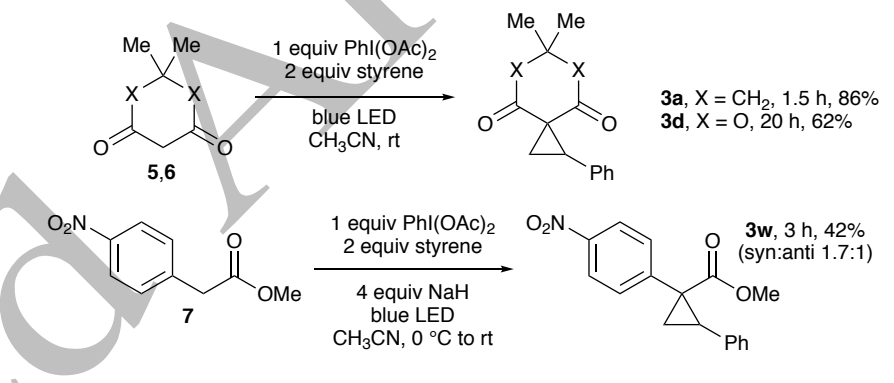

Scheme 4. Testing the tandem in situ ylide formation / cyclopropanation reaction.

Our working hypothesis for the mechanism of this reaction derives from the information gleaned through our computational and experimental studies. As irradiation of an iodonium ylide with blue LEDs does not lead to homodimerization or $\mathrm{O}-\mathrm{H}$ insertion products with $\mathrm{MeOH}^{[17]}$ (see Table 1), it is improbable that free carbenes are operative in this reaction. Furthermore, we observed an increase of reaction rates when using more electron-rich alkenes, and decreased rates with ylides expressing blue-shifted UV-Vis spectra. We propose that photoexcitation of ylide 1a leads to reversible formation of the diradical intermediate $\mathbf{A}$ that may encounter the alkene to forge the diradical B (Scheme 5). The higher rates and yields observed with electron-rich alkenes could be attributed to increased stabilization of any benzylic radical character generated in the process. Also, bond rotation within B could account for the isomerization required for the formation of $\mathbf{3 l}$ from cis- $\beta$-methylstyrene (see Schemes 3 and 5). Ring closure would give iodocyclobutane $\mathbf{C}$, and reductive elimination of iodobenzene would furnish the cyclopropane end-product 3a. A drawback of this proposal is that it would require the excited state $\mathbf{A}$ to be sufficiently long-living to encounter the alkene. Alternatively, given that natural population analysis and adaptive natural partitioning ${ }^{[19 a]}$ both concluded that iodonium ylides hold a full positive charge on the iodine atom in the ground state (eg 1a), the reaction could instead be initiated by the alkene acting 
as a Lewis base toward the iodonium, giving complex $\mathbf{D} .^{[10 a]}$ If this were to absorb a photon, it could also serve as a precursor of the diradical $\mathbf{B}$, which again would need to undergo bond reorganization, relaxation to the ground state, and reductive elimination to generate cyclopropane $\mathbf{3 a}$.
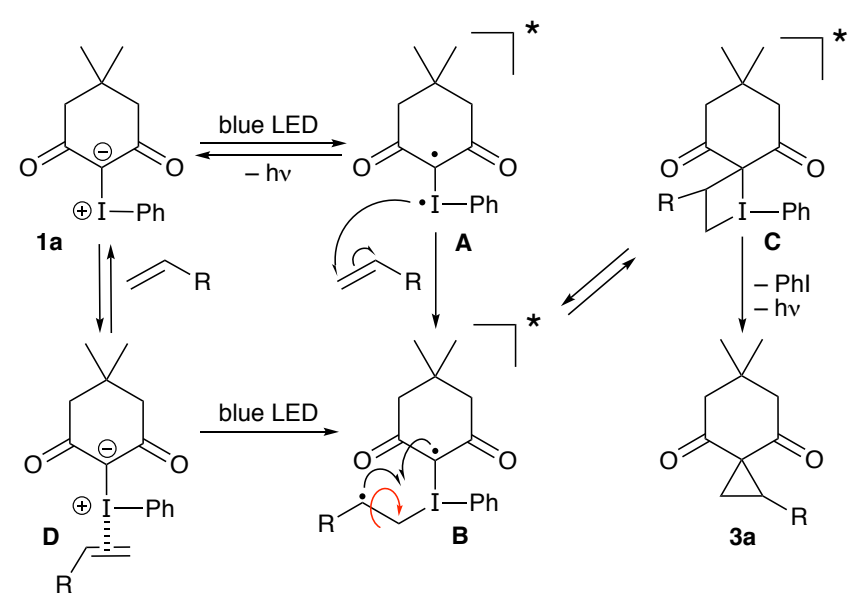

Scheme 5. Proposed reaction mechanism.

In conclusion, irradiating mixtures of iodonium ylides and alkenes with blue LEDs leads to a mild, metal-free and highly efficient synthesis of cyclopropanes. Computational analysis suggests that photoexcitation leads to a diradical species instead of free carbenes, which accounts for the excellent chemoselectivity observed. Styrenes and non-styrenyl alkenes were both viable, as were both cyclic and acyclic iodonium ylides, showing the potential generality of this new process. Furthermore, a one-pot reaction was developed starting from activated methylene ylide precursors. It is anticipated that this study will open the door to new opportunities for developing blue light-initiated reactions of hypervalent iodine reagents, possibly including catalytic and/or asymmetric variants.

\section{Experimental Section}

Into a dry 1 dram $(4.0 \mathrm{~mL})$ vial was added iodonium ylide $(0.1 \mathrm{mmol}, 1$ equiv) and $\mathrm{CH}_{3} \mathrm{CN}(1.0 \mathrm{ml}, 0.1 \mathrm{M})$, and this loaded into photo-reactor \#2 and stirred at room temperature for $2 \mathrm{~min}$, giving either a clear solution or a slurry. Styrene $(0.023 \mathrm{~mL}, 0.2 \mathrm{mmol}, 2$ equiv) was added in one portion and after stirring for $1 \mathrm{~min}$, the blue LED was turned on. The reaction mixture was stirred at room temperature until the reaction was observed to be complete by TLC or NMR analysis. The mixture was then evaporated to dryness and purified by column chromatography, eluting with mixtures of ethyl acetate and hexanes.

\section{Acknowledgements}

We would like to acknowledge the Natural Sciences and Engineering Research Council (NSERC) of Canada, the University of Waterloo and the Initiative of Excellence (IdEx) of the University of Bordeaux (Bordeaux-Waterloo joint grant program for emerging cooperation) for funding. This research was enabled in part by support provided by Compute Canada (www.computecanada.ca). We also thank Dr. Mónica Barra and Dr. Sonny Lee for helpful discussions and instrument access.
Keywords: cyclopropanation - computational analysis • hypervalent iodine $\cdot$ iodonium ylides $\cdot$ LED photochemistry

[1] a) V. Zhdankin, Hypervalent lodine Chemistry: Preparation, Structure, and Synthetic Applications of Polyvalent lodine Compounds, John Wiley \& Sons, 2013; b) T. Wirth, Hypervalent lodine Chemistry, Springer-Verlag, Berlin, 2016; c) A. Yoshimura; V. V. Zhdankin Chem. Rev. 2016, 116, 3328-3435; d) PATAl'S Chemistry of Functional Groups, I. Marek, B. Olofsson, Z. Rappoport (Ed.), Wiley, New York 2018.

[2] a) R. D. Richardson; T. Wirth Angew. Chem., Int. Ed. 2006, 45, 44024404; Angew. Chem. 2006, 45, 4402-4404; b) T. Dohi; Y. Kita Chem. Commun. 2009, 2073-2085; c) F. V. Singh; T. Wirth Chem. Asian. J. 2014, 9, 950-971; d) A. Flores; E. Cots; J. Bergès; K. Muñiz Adv. Synth. Catal. 2019, 361, 2-25; e) M. Ochiai; K. Miyamoto Eur. J. Org. Chem. 2008, 4229-4239; f) R. Francke Current Opinion in Electrochemistry 2019, 15, 83-88; g) A. Claraz; G. Masson Org. Biomol. Chem. 2018, 16, 5386-5402; h) S. Quideau; G. Lyvinec; M. Marguerit; K. Bathany; A. Ozanne-Beaudenon; T. Buffeteau; D. Cavagnat; A. Chénedé Angew. Chem., Int. Ed. 2009, 48, 4605-4609; Angew. Chem. 2009, 121, 46754679.

[3] For relevant reviews see a) K. Jia; Y. Chen, Photochemistry of hypervalent iodine compounds in PATAl'S Chemistry of Functional Groups, 2018; b) L. Wang; J. Liu Eur. J. Org. Chem. 2016, 1813-1824; For recent examples see c) J.-J. Dai W.-M. Zhang; Y.-J. Shu; Y.-Y. Sun; J. Xu; Y.-S. Feng; H.-J. Xu Chem. Commun. 2016, 52, 6793-6796; d) H. Huang; G. Zhang; L. Gong; S. Zhang; Y. Chen J. Am. Chem. Soc. 2014, 136, 2280-2283; e) H. Huang; K. Jia; Y. Chen Angew. Chem., Int. Ed. 2015, 54, 1881-1884; Angew. Chem. 2015, 127, 1901-1904; f) G.-X Li; C. A. Morales-Rivera; Y. Wang; F. Gao; G. He; P. Liu; G. Chen Chem. Sci. 2016, 7, 6407-6412; g) P. Xu; A. Abdukader; K. Hu; Y. Cheng; C. Zhu Chem. Commun. 2014, 50, 2308-2310.

[4] For relevant reviews see a) C. K. Prier; D. A. Rankic; D. W. C. MacMillan Chem. Rev. 2013, 113, 5322-5363; b) C.-S. Wang; P. H. Dixneuf; J.-F. Soulé Chem. Rev. 2018, 118, 7532-7585; c) R. C. McAtee; E. J. McClain; C. R. J. Stephenson Trends in Chemistry 2019, 1, 111-125; d) M. Reckenthäler; A. G. Griesbeck Adv. Synth. Catal. 2013, 355, 2727-2744; e) N. A. Romero; D. A. Nicewicz Chem. Rev. 2016, 116, 10075-10166.

[5] a) J. Tao; T. N. Tuck; G. K. Murphy Synthesis 2016, 48, 772-782; b) J. Tao; C. D. Estrada; G. K. Murphy Chem. Commun. 2017, 53, 90049007; c) T. Chidley; G. K. Murphy Org. Biomol. Chem. 2018, 16, 84868490; d) P. E. Ho; J. Tao; G. K. Murphy Eur. J. Org. Chem. 2013, 65406544; e) B. A. Laevens; J. Tao; G. K. Murphy J. Org. Chem. 2017, 82, 11903-11908.

[6] a) M. S. Yusubov; A. Yoshimura; V. V. Zhdankin Arkivoc 2016, 1, 342374; b) S. Chelli; K. Troshin; P. Mayer; S. Lakhdar; A. R. Ofial; H. Mayr J. Am. Chem. Soc. 2016, 138, 10304-10313.

[7] a) A. Antos; Y. Elemes; A. Michaelides; J. A. Nyxas; S. Skoulika; L. P. Hadjiarapoglou J. Org. Chem. 2012, 77, 10949-10954; b) E. D. Matveeva; T. A. Podrugina; Y. K. Grishin; A. S. Pavlova; N. S. Zefirov Russ. J. Org. Chem. 2007, 43, 201-206; c) E. D. Matveeva; T. A. Podrugina; A. S. Pavlova; A. V. Mironov; A. A. Borisenko; R. Gleiter; N. S. Zefirov J. Org. Chem. 2009, 74, 9428-9432; d) V. V. Zhdankin; O. Maydanovych; J. Herschbach; J. Bruno; E. D. Matveeva; N. S. Zefirov J. Org. Chem. 2003, 68, 1018-1023; e) M. Ochiai; Y. Kitagawa Tetrahedron Lett. 1998, 39, 5569-5570; f) M. Ochiai; Y. Kitagawa; S. Yamamoto J. Am. Chem. Soc. 1997, 119, 11598-11604.

[8] a) C. Batsila; E. P. Gogonas; G. Kostakis; L. P. Hadjiarapoglou Org. Lett. 2003, 5, 1511-1514; b) W. Adam; E. P. Gogonas; L. P. Hadjiarapoglou Tetrahedron 2003, 59, 7929-7934; c) M. B. Camacho; A. E. Clark; T. A. Liebrecht; J. P. DeLuca J. Am. Chem. Soc. 2000, 122, 5210-5211; d) R. M. Moriarty; E. J. May; O. Prakash Tetrahedron Lett. 1997, 38, 4333-4336.

[9] a) Y. R. Lee; S. H. Yoon Synth. Commun. 2006, 36, 1941-1951; b) C. J. Zhu; A. Yoshimura; P. Solntsev; L. Ji; Y. Y. Wei; V. N. Nemykin; V. V. Zhdankin Chem. Commun. 2012, 48, 10108-10110; c) E. P. Gogonas; L. P. Hadjiarapoglou Tetrahedron Lett. 2000, 41, 9299-9303; d) A. Asouti; L. P. Hadjiarapoglou Tetrahedron Lett. 1998, 39, 9073-9076; e) P. Muller; D. Fernandez Helv. Chim. Acta 1995, 78, 947-958; f) S. Spyroudis; P. Tarantili J. Org. Chem. 1993, 58, 4885-4889; g) L. Hadjiarapoglou; K. Schank Tetrahedron Lett. 1989, 30, 6673-6676; h) D. Kalpogiannaki; C.-I. Martini; A. Nikopoulou; J. A. Nyxas; V. Pantazi; L. P. Hadjiarapoglou Tetrahedron 2013, 69, 1566-1575; i) W. Adam; E. P. Gogonas; L. P. Hadjiarapoglou J. Org. Chem. 2003, 68, 9155-9158; j) S. Kalogiannis; S. Spyroudis J. Org. Chem. 1990, 55, 5041-5044.

[10] a) A. E. Bosnidou; D. Kalpogiannaki; S. Karanestora; J. A. Nixas; L. P. Hadjiarapoglou J. Org. Chem. 2015, 80, 1279-1283; b) S. R. Goudreau; D. Marcoux; A. B. Charette J. Org. Chem. 2009, 74, 470-473; c) R. M. Moriarty; O. Prakash; R. K. Vaid; L. Zhao J. Am. Chem. Soc. 1989, 111, 6443-6444; d) R. M. Moriarty; S. Tyagi; M. Kinch Tetrahedron 2010, 66, 5801-5810; e) R. P. Wurz; A. B. Charette Org. Lett. 2005, 7, 23132316; f) P. Müller; C. Boléa Helv. Chim. Acta 2001, 84, 1093-1111; g) R. M. Moriarty; J. Kim; L. Guo Tetrahedron Lett. 1993, 34, 4129-4132; h) P. Müller; Y. Allenbach; E. Robert Tetrahedron: Asymmetry 2003, 14, 779785; i) H. T. Bonge; T. Hansen Synlett 2007, 55-58. 
[11] a) S. Mo; X. Li; J. Xu J. Org. Chem. 2014, 79, 9186-9195; b) G. K. Murphy; F. G. West Org. Lett. 2006, 8, 4359-4361.

[12] For relevant examples see a) P. Muller; Y. F. Allenbach; S. Chappellet; A. Ghanem Synthesis 2006, 1689-1696; b) B. Moreau; A. B. Charette $J$. Am. Chem. Soc. 2005, 127, 18014-18015; c) B. Moreau; D. Alberico; V. N. G. Lindsay; A. B. Charette Tetrahedron 2012, 68, 3487-3496; d) B. Xu; U. K. Tambar Angew. Chem., Int. Ed. 2017, 56, 9868-9871; Angew. Chem. 2017, 129, 10000-10003.

[13] For reviews on the chemistry of doubly activated cyclopropanes see a) H. U. Reissig; R. Zimmer Chem. Rev. 2003, 103, 1151-1196; b) M. Yu B. L. Pagenkopf Tetrahedron 2005, 61, 321-347; c) M. Rubin; M. Rubina; V. Gevorgyan Chem. Rev. 2007, 107, 3117-3179; d) C. A. Carson; M. A. Kerr Chem. Soc. Rev. 2009, 38, 3051-3060; e) H. Nambu; M. Fukumoto; W. Hirota; T. Yakura Org. Lett. 2014, 16, 4012 4015; f) M. A. Cavitt; L. H. Phun; S. France Chem. Soc. Rev. 2014, 43, 804-818; g) C.-H. Lin; B. Plietker Isr. J. Chem. 2016, 56, 409-416; h) H Nambu; Y. Onuki; N. Ono; T. Yakura Adv. Synth. Catal. 2018, 360, 2938-2944.

[14] a) R. Ballini; A. Palmieri; D. Fiorini Arkivoc 2007, 172-194; b) R. P. Wurz; A. B. Charette Org. Lett. 2003, 5, 2327-2329; c) O. Lifchits; A. B. Charette Org. Lett. 2008, 10, 2809-2812.

[15] a) E. D. Matveeva; T. A. Podrugina; A. S. Pavlova; A. V. Mironov; R Gleiter; N. S. Zefirov Eur. J. Org. Chem. 2009, 2323-2327; b) E. D. Matveeva; T. A. Podrugina; M. A. Taranova; A. A. Borisenko; A. V. Mironov; R. Gleiter; N. S. Zefirov J. Org. Chem. 2011, 76, 566-572.

[16] a) M. Papadopoulou; S. Spyroudis; A. Varvoglis J. Org. Chem. 1985 $50,1509-1511$; b) E. Malamidoli-Xenikaki; S. Spyroudis Synlett 2008, 2725-2740.

[17] I. D. Jurberg; H. M. L. Davies Chem. Sci. 2018, 9, 5112-5118.

[18] For further work on blue LED-mediated reactions of phenyldiazoacetate derivatives see a) R. Hommelsheim; Y. Guo; Z. Yang; C. Empel; R. M. Koenigs Angew. Chem., Int. Ed. 2019, 58, 1203-1207; Angew. Chem. 2019, 131, 1216-1220; b) S. Jana; R. M. Koenigs Asian J. Org. Chem. 2019, 8, 683-686; c) Z. Yang; Y. Guo; R. M. Koenigs Chem. Eur. J. 2019, 25, 6703-6706; d) F. He; R. M. Koenigs Chem. Commun. 2019 55, 4881-4884; e) J. Yang; J. Wang; H. Huang; G. Qin; Y. Jiang; T. Xiao Org. Lett. 2019, 21, 2654-2657. For a recent example of LEDmediated generation of carbenes from pyridotriazoles see f) Z. Zhang D. Yadagiri; V. Gevorgyan Chem. Sci. 2019, 10.1039/C9SC02448D.

[19] a) A. S. Ivanov; I. A. Popov; A. I. Boldyrev; V. V. Zhdankin Angew. Chem., Int. Ed. 2014, 53, 9617-9621; Angew. Chem. 2014, 126, 9771 9775.

[20] a) G. S. Sinclair; R. Tran; J. Tao; W. S. Hopkins; G. K. Murphy Eur. J. Org. Chem. 2016, 4603-4606; b) Z. Zhao; K. C. Y. Ma; C. Y. Legault; G. K. Murphy Chem. Eur. J. 2019, DOI: 10.1002/chem.201804786.

[21] a) W. J. Hehre; R. Ditchfield; J. A. Pople J. Chem. Phys. 1972, 56, 2257-2261; b) P. C. Hariharan; J. A. Pople Theor. Chim. Acta 1973, 28 , 213-222.

[22] a) A. E. Reed; R. B. Weinstock; F. Weinhold J. Chem. Phys. 1985, 83 735-746; b) E. D. Glendening; C. R. Landis; F. Weinhold J. Comput Chem. 2013, 34, 1429-1437.

[23] The products of ketoester-derived ylide 1i underwent rapid conversion to the corresponding dihydrofuran upon purification, so no additiona cyclopropanation examples are provided. Cyclopropanations attempted with disulfonyl iodonium ylide $1 \mathrm{p}$ were unsuccessful, as this was inert under the reaction conditions.

[24] Alkene photoisomerization was not responsible for the stereochemical outcome observed with 3 I. Irradiating cis- $\beta$-methylstyrene with blue light for $24 \mathrm{~h}$ failed to produce any quantity of the trans-isomer observable by ${ }^{1} \mathrm{H}$ NMR.

[25] There are conflicting literature reports as to whether the characterization data recorded for $3 \mathbf{l}$ corresponds to syn- or anticyclopropane isomer. For its identification as the syn-isomer see Y.-R. Lee; J.-H. Choi Bull. Korean Chem. Soc. 2006, 27, 503-507. For its identification as the anti-isomer see Ref. 10h. The recorded crystal structure unambiguously shows compound $3 \mathbf{l}$ to be the anti-isomer.

[26] a) V. V. Zhdankin; J. D. Protasiewicz Coord. Chem. Rev. 2014, 275 54-62; b) C. J. Zhu; A. Yoshimura; L. Ji; Y. Y. Wei; V. N. Nemykin; V. V. Zhdankin Org. Lett. 2012, 14, 3170-3173.

[27] a) J. Vaitla; K. H. Hopmann; A. Bayer Org. Lett. 2017, 19, 6688-6691; b) H. T. Bonge; T. Hansen Tetrahedron Lett. 2008, 49, 57-61.

[28] a) To rule out a radical mechanism involving photoinititated decomposition of $\mathrm{Phl}(\mathrm{OAc})_{2}$ by blue light, it was irradiated for $4 \mathrm{~h}$, after which quantitative ${ }^{1} \mathrm{H}$ NMR showed it to be $94 \%$ unchanged. For an example of radical reactions of iodonium ylides see a) M. Hartmann; $Y$. Li; C. Mück-Lichtenfeld; A. Studer Chem. Eur. J. 2016, 22, 3485-3490; For a recent example of visible light-initiated reactions of $\mathrm{Phl}(\mathrm{OAc})_{2}$ see b) C. F. Meyer; S. M. Hell; A Misale; A A Trabanco; V. Gouverneur Angew. Chem., Int. Ed. 2019, 58, 8829-8833; Angew. Chem. 2019, 131, $8921-8925$ 